\title{
Geographic Variation in the Prevalence of High-Risk Medication Use Among Medicare Part D Beneficiaries by Hospital Referral Region
}

\author{
Chanadda Chinthammit, BSPharm, MS, PhD; Sandipan Bhattacharjee, BPharm, MS, PhD; \\ David R. Axon, PhD, MPharm, MS; Marion Slack, PhD; John P. Bentley, PhD; Terri L. Warholak, PhD; \\ Debbie L. Wilson, PhD; and Wei-Hsuan Lo-Ciganic, PhD, MS, MSPharm
}

\begin{abstract}
BACKGROUND: Understanding geographic patterns of high-risk medication (HRM) prescribed and dispensed among older adults may help the Centers for Medicare \& Medicaid Services and their partners develop and tailor prevention strategies.
\end{abstract}

OBJECTIVE: To compare the geographic variation in the prevalence of HRM use among Medicare Part D beneficiaries from 2011 to 2013, for Medicare Advantage Prescription Drug (MA-PD) plans and stand-alone Prescription Drug Plans (PDPs).

METHODS: This retrospective study used the data of a $5 \%$ national Medicare sample (2011-2013). Beneficiaries were included in the study if they were aged $\geq 65$ years, continuously enrolled in MA-PDs or PDPs ( $\sim 1.3$ million each year), and had $\geq 2$ prescriptions for the same HRM (e.g., amitriptyline) prescribed and dispensed during the year based on the Pharmacy Quality Alliance's (PQA) quality measures for HRM use. Multivariable logistic regression was used to estimate adjusted annual HRM use rates (i.e., adjusted predictions, average marginal predictions, or model-adjusted risk) across 306 Dartmouth Atlas of Health Care hospital referral regions (HRRs), controlling for sociodemographic, health-status, and access-to-care factors.

RESULTS: Among eligible beneficiaries each year (1,161,076 in 2011, $1,237,653$ in 2012 , and $1,402,861$ in 2013 ), nearly $40 \%$ were enrolled in MA-PD plans, whereas the remaining $60 \%$ were in PDP plans. The adjusted prevalence of HRM use significantly decreased among Medicare beneficiaries enrolled in MA-PD $(13.1 \%-8.4 \%, P<0.001)$ and PDP (16.2\%-12.2\%, $P<0.001$ ) plans from 2011 to 2013. For MA-PD and PDP beneficiaries, HRM users were more likely to be (all $P<0.001$ ) the following: female (MA-PD: $70.4 \%$ vs. $59.9 \%$; PDP: $72.8 \%$ vs. $62.5 \%$ ); White (MA-PD: $84.6 \%$ vs. $81.4 \%$; PDP: $86.6 \%$ vs. $85.3 \%$ ); with low-income subsidy or dual eligibility for Medicaid (MA-PD: $22.3 \%$ vs. $16.6 \%$; PDP: $29.2 \%$ vs. $23.3 \%$ ); and disabled (MA-PD: $15.6 \%$ vs. $8.7 \%$; PDP: $15.4 \%$ vs. $8.5 \%$ ) compared with non-HRM users in 2013. In 2013, significant geographic variation existed, with the ratios of 75 th-25th percentiles of HRM use rates across HRRs as 1.42 for MA-PDs and 1.31 for PDPs. For MA-PDs, the top 5 HRRs with the highest HRM use rates in 2013 were Casper, WY (20.4\%), Waco, TX (16.7\%), Lubbock, TX (15.7\%), Santa Barbara, CA (15.2\%), and Temple, TX (15.1\%); for PDPs, they were Lawton, OK (18.8\%), Alexandria, LA (18.8\%), Lake Charles, LA (18.6\%), Oklahoma City, OK (18.0\%), and Slidell, LA (18.0\%).

CONCLUSIONS: Substantial geographic variation exists in the prevalence of HRM use among older adults in Medicare, regardless of prescription drug plan. Areas with high prevalence of HRM use may benefit from targeted interventions (e.g., medication therapy management monitoring or alternative medication substitutions) to prevent potential adverse consequences.

J Manag Care Spec Pharm. 2020;26(10):1309-16

Copyright $\odot 2020$, Academy of Managed Care Pharmacy. All rights reserved.

\section{What is already known about this subject}

Older adults have a higher risk of adverse drug events than younger adults because of age-related drug metabolism changes and their multiple comorbidities.

Adverse drug events because of high-risk medication (HRM) use, such as falls with benzodiazepine use, among older adults are associated with a substantial clinical and economic burden in the United States.

Previous reports suggested geographic variation of HRM use, based on the Healthcare Effectiveness Data and Information Set (HEDIS), in beneficiaries enrolled in stand-alone Prescription Drug Plans (PDPs).

\section{What this study adds}

This study was the first to examine geographic variation of HRMs prescribed and dispensed patterns for Medicare Advantage Prescription Drug (MA-PD) plans and stand-alone PDPs using the Pharmacy Quality Alliance's HRM measure, which is included in the Centers for Medicare \& Medicaid Services' star ratings.

Our findings showed that substantial geographic variation in HRM use exists among Medicare Part D enrollees regardless of Part D plan types and areas at high-risk of HRM use differed between MA-PD plans and PDPs.

Plan sponsors and health care systems may strategize and prioritize targeted interventions for the areas with high HRM use prevalence to prevent potential adverse health outcomes.

T. nappropriate medication use is more common among older adults (varying from $12.3 \%$ to $42.6 \%$ based on different definitions) compared with younger individuals because of aging along with multiple comorbid conditions. ${ }^{1-7}$ Inappropriate medication use may contribute to changes and reduction in hepatic metabolism and renal clearance among older adults and thus enhance drug toxicity. ${ }^{8}$ Inappropriate medication use related to adverse health outcomes causes a substantial clinical and economic burden, with an estimated annual cost of $\$ 7.2$ billion in the United States. ${ }^{9-11}$

Several organizations and stakeholders have developed guidelines and policies to prevent inappropriate medication use among older adults. For example, the Beers Criteria, first 
published in 1991, ${ }^{12-14}$ has been widely adopted by health care organizations to reduce potentially inappropriate medication use. In 2013, the Pharmacy Quality Alliance (PQA) adapted subsections of the Beers Criteria and developed a measure to identify older adults with high-risk medications (HRM) use when alternative medications were available. ${ }^{15-17}$ In 2015, the Centers for Medicare \& Medicaid Services (CMS) included the PQA's HRM measure in the star rating system for Medicare Part D plans. ${ }^{18-20}$ Meanwhile, health plans also sought to decrease HRM use through different strategies such as prior authorization, formulary selection, educational mailings to prescribers, and performing comprehensive medication reviews as part of medication therapy management (MTM) services. ${ }^{18,21}$ These approaches may be effective to some extent; however, strategies to more accurately and effectively identify high-risk individuals or areas are needed to better guide these interventions.

Previously, CMS has reported geographic variation in HRM use at the state level in the whole Medicare Part D population. ${ }^{22}$ However, use of health services and prescription medications varies substantially within the same state, thus, hospital referral regions (HRRs) may better reflect health services resources and utilization in a particular geographical area. HRRs are commonly used regional units developed by the Dartmouth Atlas of Health Care to examine geographic variation in a variety of topics such as health care spending and chronic disease management, especially in Medicare services. ${ }^{23-25}$ HRRs are intended to approximate regional health care markets for tertiary medical care. ${ }^{23}$ Each HRR contains at least 1 hospital that performs major cardiovascular procedures and neurosurgery. ${ }^{23}$

Previously, Zhang et al. (2010) evaluated HRM use among stand-alone Prescription Drug Plan (PDP) beneficiaries at the HRR level, using the Health Effectiveness Data Information Set (HEDIS) measure. ${ }^{26-28}$ However, the HEDIS HRM list was not as thorough as the PQA HRM list. At the time of this study, the HEDIS HRM only required Medicare beneficiaries to have received 1 HRM, ${ }^{29}$ whereas the PQA HRM measure required beneficiaries to have 2 or more prescription fills for the same HRM during the measurement period..$^{30}$ The PQA measure therefore offers an opportunity for a more conservative/targeted analysis than using the HEDIS measure.

Furthermore, over 30\% of Medicare Part D beneficiaries are enrolled in Medicare Advantage Prescription Drug (MA-PD) plans. There are important differences between the structure of MA-PD plans and PDPs, in particular MA-PD plans have greater incentives to lower health care costs than PDPs through the provision of quality bonus payments, so MA-PD plans may use more aggressive strategies to monitor HRM use. ${ }^{31}$ Thus, it is important to assess the magnitude of HRM use in MA-PD plans and PDPs. ${ }^{32}$
The objective of this study was to examine HRM use in MA-PD and PDP beneficiaries across HRRs using the PQA measure from 2011 to 2013, adjusting for demographic, health status, and access to care factors. Understanding geographic patterns of HRM use among older adults by type of Part D plans may help CMS and their partners develop and tailor prevention strategies.

\section{Methods}

\section{Study Design and Data Sources}

This retrospective cross-sectional study used Medicare Master Beneficiary Summary Files (MBSF) and Part D Prescription Drug Event (PDE) files for a 5\% nationally representative sample of Medicare beneficiaries from 2011 to 2013 ( $\sim 3.2$ million unique beneficiaries). MBSF included sociodemographic and eligibility information. ${ }^{27}$ PDE files contained information regarding the prescriptions filled and reimbursed by Part D plans including medication names, National Drug Code (NDC) numbers, quantity, prescription fill date, days of supply, and prescriber's national provider identifier. ${ }^{28}$ We obtained regional and access-to-care factors from the publicly available Area Health Resource File (AHRF) for the year 2013-2014 through the Medicare beneficiaries' social administration codes. AHRF includes more than 6,000 regional variables regarding health facilities, health professions, measures of resource scarcity, health status, economic activity, training programs for health care professionals, and socioeconomic and environmental characteristics. Variables from AHRF data included in this study were rural/urban continuum (metropolitan vs. nonmetropolitan), primary care shortage area (partial, full, or none), and mental health care shortage area (partial, full, or none). The University of Arizona Institutional Review Board approved this study. The reporting of this study complied with the STROBE guidelines. ${ }^{33}$

\section{Study Sample Each Year}

Supplementary Figure 1 (available in online article) outlines the selection of the study sample for each calendar year (2011, 2012, 2013). Beneficiaries aged $\geq 65$ years who were continuously enrolled in either a Medicare Part D MA-PD plan or a PDP for the entire 12 months were included in the final study sample. Beneficiaries who were not U.S. residents, died, had end-stage renal disease, did not fill a prescription, or switched between MA-PD plans and PDPs during the year were excluded.

\section{Dependent Variable: High-Risk Medication Use}

Using the PQA's HRM measure released in 2013, we first identified claims containing HRMs across 9 therapeutic classes, including anticholinergics (excluding tricyclic antidepressants), anti-infectives, anti-thrombotics, cardiovascular medications, central nervous system medications, endocrine medications, 
gastrointestinal medications, pain medications, and skeletal and muscle relaxants (Supplementary Table 1, available in online article). Beneficiaries who had at least 2 prescription fills for the same HRM during the year met the PQA's HRM use criteria (i.e., HRM users). Using beneficiary-level data, we calculated crude prevalence as the proportion of beneficiaries with HRM use among beneficiaries in MA-PD plans versus PDPs each year. ${ }^{34}$

\section{Independent Variable: Hospital Referral Regions}

The independent variable was the 306 Dartmouth Atlas of Health Care HRRs, which were aggregated from 3,436 hospital service areas based on where the largest proportion of major cardiovascular and neurosurgery procedures were performed. Each HRR has at least 1 town or city where major cardiovascular surgical procedures and neurosurgery are performed. ${ }^{35}$ For each year, we assigned each beneficiary to an HRR based on their residential ZIP code that was obtained from the MBSF of the year. ${ }^{36}$

\section{Covariates}

Sociodemographic characteristics included age, sex, race/ ethnicity (White, Black, Hispanic, and Others), having lowincome subsidy (LIS) or dual eligibility (DE) for Medicaid, with disability status based on the original reason for Medicare entitlement. Health status factors included beneficiaries' comorbidities measured by the modified RxRisk-V score, and numbers of unique pharmacies and unique providers visited during the year.

Although many calculations of comorbidity scores require using medical claims data, it is worth noting that the HRM measure included in the CMS star rating system was calculated based on prescription drug claims alone because some health plans only have access to prescription drug claims data. Therefore, we used prescription drug claims alone to calculate the modified RxRisk-V score (excluding HRM medications) as a proxy of beneficiary comorbidity complexity that is applicable to all Part D health plans. ${ }^{37,38}$ The RxRisk-V, developed as an all-age risk adjustment tool, is a prescription-based risk adjustment score that uses ambulatory pharmacy data to identify 42 chronic disease categories. RxRisk-V has been used to predict total health care costs and mortality. ${ }^{37,39-42}$ A previous study showed that the RxRisk-V model performed similarly to the Ambulatory Clinical Group, a diagnostic-based model. ${ }^{42}$

\section{Statistical Analysis}

The annual crude prevalence of HRM use was calculated by dividing the number of beneficiaries with at least 2 prescription fills for the same HRM by the total number of beneficiaries for each HRR each year by MA-PD plan versus PDP.

Our analytical approaches consisted of 2 steps. Separate models were created for MA-PD and PDP beneficiaries. First, multivariable logistic regression was used to estimate adjusted annual prevalence of HRM use (also called average marginal predictions or model-adjusted risk) for each HRR, controlling for demographics, health status, and regional/access-to-case factors. Second, HRRs were ranked based on the adjusted prevalence of HRM use from highest to lowest. We calculated the ratios of 75th to 25th percentile of adjusted HRM use rates; a ratio greater than 1 suggests geographic variation. ${ }^{43}$ All statistical analyses were performed using SAS version 9.4 (SAS Institute, Cary, NC).

\section{Results}

\section{Beneficiary Characteristics}

There were $1,161,076,1,237,653$, and 1,402,861 eligible beneficiaries in 2011, 2012, and 2013 analytical samples, respectively. Of these, approximately $40 \%$ of the Part D beneficiaries were enrolled in MA-PD plans (2011: 39\%; 2012: 39\%; 2013: 37\%), and 60\% were enrolled in PDPs (2011: 61\%; 2012: 61\%; 2013: 63\%; Supplementary Figure 1, available in online article).

Sociodemographic, health status, and regional or accessto-care factors were similar across years. The 2013 data are presented in Table 1. Compared with MA-PD beneficiaries, PDP beneficiaries were more likely to be older (mean age: $75.6 \pm 7.8$ years vs. $74.7 \pm 7.3$ years), female ( $64.0 \%$ vs. $61.0 \%$ ), White ( $85.5 \%$ vs. $81.7 \%$ ), to have LIS/DE (24.2\% vs. $17.2 \%$ ), $\geq 3$ prescribers ( $58.7 \%$ vs. $54.5 \%), \geq 2$ pharmacies ( $46.1 \%$ vs. 45.7\%), higher RxRisk-V index score ( $4.5 \pm 2.8$ vs. $4.1 \pm 2.7$ ), to live in midwestern and southern regions (63.8\% vs. $49.7 \%$ ) and to live in non-metropolitan areas $(22.6 \%$ vs. $10.3 \%$; all $P<0.001)$. Compared with PDP beneficiaries, MA-PD beneficiaries were more likely to live in the areas with some extent of shortage in primary care $(92.5 \%$ vs. $89.3 \%)$ or mental care (91.6\% vs. $89.6 \%$; all $P<0.001$ ).

\section{HRM Use and Geographic Variation}

The prevalence of HRM use significantly decreased from 2011 to 2013 for MA-PD plans (13.2\% in 2011, 11.4\% in 2012, and 8.7\% in 2013; $\mathrm{p}_{\text {trend }}<0.001$ ) and PDPs (15.8\% in 2011, $13.9 \%$ in 2012, and $11.9 \%$ in 2013; $\mathrm{p}_{\text {trend }}<0.001$ ). For MA-PD plans and PDPs, adjusted HRM use rates varied substantially across 306 HRRs in 2011, 2012, and 2013, although the overall decreasing trend from 2011 to 2013 was found across HRRs (Supplementary Table 2, available in online article). Among MA-PD beneficiaries, HRM use rates ranged from $4.8 \%$ to $31.7 \%$ among 306 HRRs (5th-95th percentile, 9.2\%-20.5\%) in $2011 ; 4.1 \%-26.0 \%$ (5th-95th percentile, $8.0 \%-16.7 \%$ ) in 2012; and 3.3\%-20.4\% (5th-95th percentile, 5.0\%-12.6\%) in 2013 (Figure 1 and Supplementary Figure 2, available in online article). The ratios of 75 th-25th percentile of HRM use rates across HRRs were 1.43 for 2011, 1.40 for 2012, and 1.42 for 2013. Among PDP beneficiaries, HRM use rates ranged from $8.7 \%$ to $24.9 \%$ among 306 HRRs (5th-95th percentile, 
TABLE 1 Medicare Beneficiaries Aged 65 Years or Older with MA-PD Plans and PDPs, 2013: Demographics and Characteristics Overall and by High-Risk Medication Use

\begin{tabular}{|c|c|c|c|c|c|c|c|}
\hline & \multicolumn{3}{|c|}{ MA-PD Beneficiaries } & \multicolumn{4}{|c|}{ PDP Beneficiaries } \\
\hline & $\begin{array}{c}\text { Total } \\
(\mathrm{N}=521,546) \\
\end{array}$ & $\begin{array}{c}\text { HRM Users } \\
(\mathrm{n}=53,699,10.2 \%)\end{array}$ & $\begin{array}{c}\text { Non-HRM Users } \\
(\mathrm{n}=467,847,89.7 \%)\end{array}$ & $\begin{array}{c}\text { Total } \\
(\mathrm{N}=881,315) \\
\end{array}$ & $\begin{array}{c}\text { HRM Users } \\
(\mathrm{n}=124,763,14.2 \%)\end{array}$ & \multicolumn{2}{|c|}{$\begin{array}{c}\text { Non-HRM Users } \\
(\mathrm{n}=756,552,85.8 \%)\end{array}$} \\
\hline \multicolumn{8}{|l|}{ Sociodemographics } \\
\hline Age, mean (SD) a & $(7.3)$ & $(7.0)$ & $(7.3)$ & $(7.8)$ & $(7.6)$ & 75.6 & $(7.9)$ \\
\hline Female, n (\%) & $318,033 \quad(61.0)$ & $37,803 \quad(70.4)$ & $280,230 \quad(59.9)$ & $563,939 \quad(64.0)$ & $90,812 \quad(72.8)$ & 473,127 & $(62.5)$ \\
\hline \multicolumn{8}{|l|}{ Race, $\mathrm{n}(\%)^{\mathrm{a}}$} \\
\hline White & 426,103 & 45,430 & 380,673 & 753,661 & 108,087 & 645,574 & $(85.3)$ \\
\hline Black & 51,396 & 4,792 & 46,604 & 67,457 & 9,265 & 58,192 & $(7.7)$ \\
\hline Hispanic & 13,905 & 1,372 & 12,533 & 17,897 & 2,387 & 15,510 & $(2.1)$ \\
\hline Others & 30,142 & 2,105 & 28,037 & 42,300 & 5,024 & 37,276 & $(4.9)$ \\
\hline LIS/DE, n (\%)a & $89,715 \quad(17.2)$ & $11,966 \quad(22.3)$ & 77,749 & 213,114 & 36,485 & 176,629 & (23.3) \\
\hline Disabled, n (\%) & 49,318 & $(15.6)$ & 40,920 & 83,601 & 19,153 & 64,448 & $(8.5)$ \\
\hline \multicolumn{8}{|l|}{ Health status factors } \\
\hline \multicolumn{8}{|c|}{ Number of prescribers, $\mathrm{n}(\%)^{\mathrm{a}}$} \\
\hline $0-2$ & $237,178 \quad(45.5)$ & 14,832 & 222,346 & 363,893 & 31,752 & 332,141 & $(43.9)$ \\
\hline$\geq 3$ & $284,368 \quad(54.5)$ & 38,867 & 245,501 & 517,422 & 93,011 & 424,411 & $(56.1)$ \\
\hline \multicolumn{8}{|c|}{ Number of pharmacies, $\mathrm{n}(\%)^{\mathrm{a}}$} \\
\hline $0-1$ & $283,264 \quad(54.3)$ & 24,333 & 258,931 & $475,332 \quad(53.9)$ & 55,429 & 419,903 & $(55.5)$ \\
\hline$\geq 2$ & $238,282 \quad(45.7)$ & 29,366 & 208,916 & 405,983 & 69,334 & 336,649 & $(44.5)$ \\
\hline $\begin{array}{l}\text { Modified RxRisk-V } \\
\text { index, mean (SD)a }\end{array}$ & $4.1 \quad(2.7)$ & $(2.7)$ & $(2.6)$ & $(2.8)$ & $(2.8)$ & 4.2 & $(2.7)$ \\
\hline \multicolumn{8}{|l|}{ Regional-level factors } \\
\hline \multicolumn{8}{|l|}{ Region, $\mathrm{n}(\%)^{\mathrm{a}}$} \\
\hline Northeast & $107,016 \quad(20.5)$ & 10,300 & 96,716 & 169,451 & 19,712 & 149,739 & $(19.8)$ \\
\hline Midwest & $92,325 \quad(17.7)$ & $(16.0)$ & 83,723 & 234,289 & 29,479 & 204,810 & $(27.1)$ \\
\hline South & $166,676 \quad(32.0)$ & 19,327 & 147,349 & 327,912 & 54,207 & 273,705 & $(36.2)$ \\
\hline West & $154,328 \quad(29.6)$ & 15,359 & 138,969 & 148,463 & 21,170 & 127,293 & (16.8) \\
\hline Unknown & 1,201 & $(0.2)$ & 1,090 & 1,200 & $(0.2)$ & 1,005 & $(0.1)$ \\
\hline \multicolumn{8}{|c|}{ Rural/urban county, n (\%) ${ }^{\mathrm{a}}$} \\
\hline Metropolitan & $466,537 \quad(89.5)$ & 47,707 & 418,830 & 681,036 & 94,984 & 586,052 & $(77.5)$ \\
\hline Nonmetropolitan & $53,807 \quad(10.3)$ & $(11.0)$ & 47,926 & 199,022 & 29,575 & 169,447 & $(22.4)$ \\
\hline \multicolumn{8}{|c|}{ Resident in a primary care shortage area, $\mathrm{n}(\%)^{\mathrm{a}}$} \\
\hline Full shortage area & $198,027 \quad(38.0)$ & 20,132 & 177,895 & 293,134 & 42,334 & 250,800 & $(33.2)$ \\
\hline Partial shortage area & $283,209 \quad(54.3)$ & 29,079 & 254,130 & 492,732 & 68,883 & 423,849 & $(56.0)$ \\
\hline No shortage area & $39,108 \quad(7.5)$ & 4,377 & 34,731 & 94,192 & 13,342 & 80,850 & $(10.7)$ \\
\hline \multicolumn{8}{|c|}{ Resident in a mental care shortage area, $\mathrm{n}(\%)^{\mathrm{a}}$} \\
\hline Full shortage area & $198,768 \quad(38.1)$ & 20,601 & 178,167 & 373,485 & 55,346 & 318,139 & $(42.1)$ \\
\hline Partial shortage area & $278,002 \quad(53.3)$ & 28,459 & 249,543 & 414,670 & 56,788 & 357,882 & $(47.3)$ \\
\hline No shortage area & $43,574 \quad(8.4)$ & 4,528 & 39,046 & 91,903 & 12,425 & 79,478 & $(10.5)$ \\
\hline
\end{tabular}

$11.6 \%-22.2 \%$ ) in $2011 ; 7.4 \%-20.5 \%$ (5th-95th percentile, $10.3 \%-18.3 \%$ ) in 2012; and 6.1\%-18.9\% (5th-95th percentile, 8.8\%-16.1\%) in 2013 (Figure 2 and Supplementary Figure 3, available in online article). The ratios of 75 th-25th percentile of HRM use rates across HRRs were 1.39 for 2011, 1.36 for 2012, and 1.31 for 2013 .

\section{The Top 5 Hospital Referral Regions with Highest HRM Use Proportions}

As shown in Supplementary Table 3 (available in online article), the top 5 HRRs with the highest HRM use proportions among MA-PD beneficiaries were Anchorage, AK (31.7\%), Lawton, OK (26.7\%), Jackson, TN (26.3\%), Oxford, MS (25.2\%), and Hattiesburg, MS (23.4\%) for 2011; Casper, WY 


\section{FIGURE 1 Percentage of Beneficiaries with Use of at Least 2 High-Risk Medications Across Hospital Referral} Regions: MA-PD Beneficiaries, 2011-2013
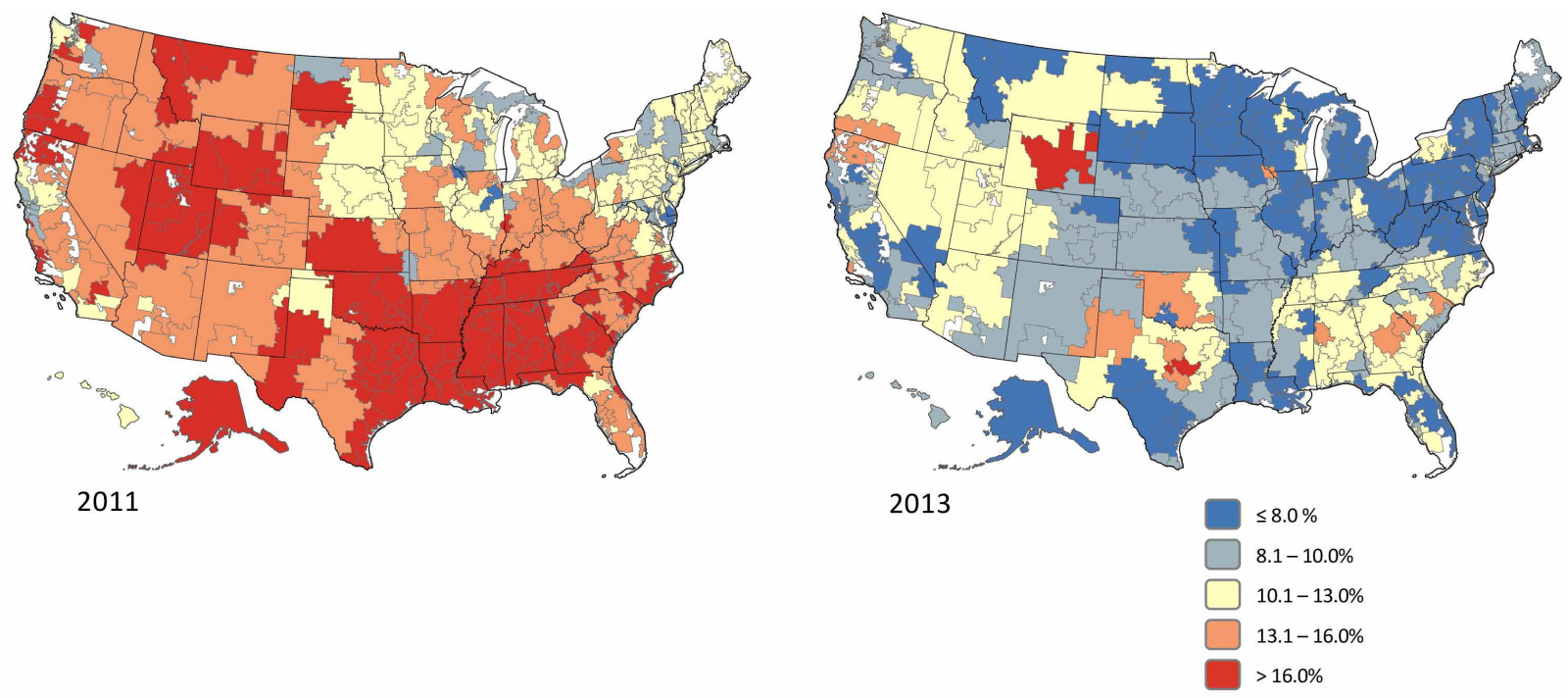

Note: The high-risk medication use rates were adjusted for age, sex, race, Part D low-income subsidy/dual eligibility status, disability status, regional characteristics (e.g., rural/urban continuum and access-to-care factors), and clinical complexity (e.g., modified RxRisk index).

MA-PD = Medicare Advantage Prescription Drug plan.

(26.0\%), Tuscaloosa, AL (21.6\%), Oxford, MS (21.0\%), Waco, TX (20.0\%), and Augusta, GA (19.2\%) for 2012; and Casper, WY (20.4\%), Waco, TX (16.7\%), Lubbock, TX (15.7\%), Santa Barbara, CA (15.2\%), and Temple, TX (15.1\%) for 2013. Casper, WY, Tuscaloosa, AL, and Augusta, GA, were consistently among the top 10 HRRs with the highest HRM use rates for MA-PD beneficiaries from 2011 to 2013. Among MA-PD beneficiaries, HRRs in Texas made up 4 out of the top 10 HRRs with highest HRM use proportions in 2013.

Among PDP beneficiaries, the top 5 HRRs with the highest HRM use proportions were Monroe, LA (24.9\%), Texarkana, AR (23.9\%), Provo, UT (23.8\%), Meridian, MS (23.6\%), and Shreveport, LA (23.4\%) for 2011; Monroe, LA (20.5\%), Lake Charles, LA (20.4\%), Alexandria, LA (20.1\%), Oklahoma City, OK, (20.1\%), and Tuscaloosa, AL (19.6\%) for 2012; and Lawton, OK (18.8\%), Alexandria, LA (18.8\%), Lake Charles, LA (18.6\%), Oklahoma City, OK (18.0\%), and Slidell, LA (18.0\%) for 2013. Monroe, LA; Lawton, OK; and Shreveport, LA were consistently 1 of the top 10 highest HRM use proportions for PDP beneficiaries over the 3-year period. Among PDP beneficiaries, HRRS in Louisiana made up most of the top 10 HRRs with highest HRM use rates in 2011, 2012, and 2013.

\section{Discussion}

This study found that prevalence of HRM use, as defined by the CMS/PQA, significantly decreased by over 25\% from 2011 to 2013 in MA-PD and PDP beneficiaries aged $\geq 65$ years, although it still remains common (approximately 9\% in MA-PD plans and 12\% in PDPs annually). In addition, our findings suggested disparities because of geographic differences remain a concern regardless of health plan type or year. After adjusting for sociodemographic, health status, and regional or access-tocare factors, HRR-level geographic variation persisted across 3 years. The majority of areas with high HRM prevalence for MA-PD and PDP beneficiaries were located in the southern United States.

Consistent with previous studies, ${ }^{44-46}$ our findings showed that the PDP beneficiaries with higher HRM prevalence were concentrated in the southern regions of the United States, while MA-PD beneficiaries with higher HRM prevalence clustered in the southern and western regions. Multifaceted factors may have contributed to the observed geographic variations in the prevalence of HRM use, especially in southern regions. Residents in the southern regions of the United States were more likely to be Black or Hispanic, dual-eligible for Medicaid, and to have higher prevalence of multiple chronic diseases and polypharmacy.

A recent report found that the areas with highest priced and health-risk adjusted Medicare spending per capita were mainly located in the southern regions. ${ }^{47}$ In addition, these areas tended to have fewer physicians available for access for care per resident and a larger need of hospital beds, surgical centers, and post-acute health care professionals. ${ }^{47}$ Another study identified 

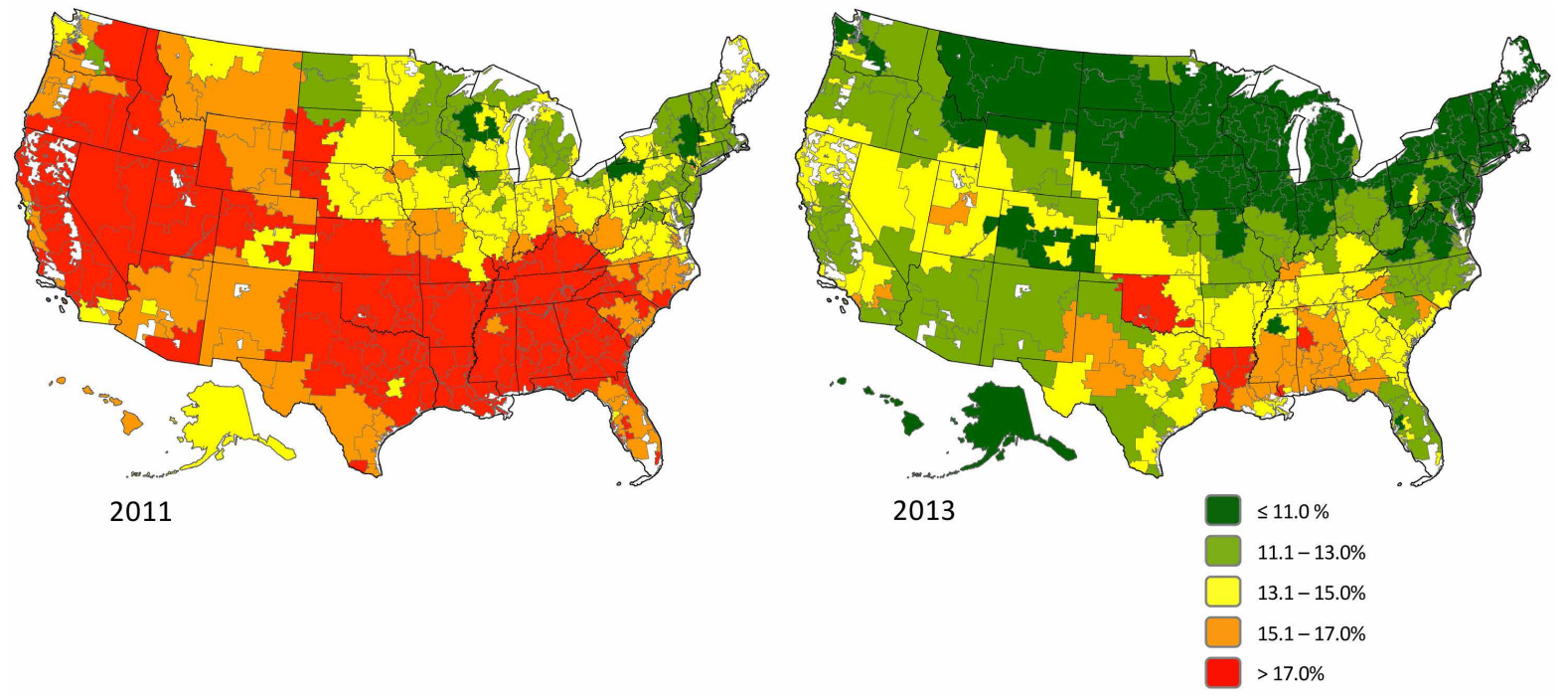

Note: The high-risk medication use prevalence was adjusted for age, sex, race, Part D low-income subsidy/dual eligibility status, disability status, regional characteristics (e.g., rural/urban continuum and access-to-care factors), and clinical complexity (e.g., modified RxRisk index).

PDP = stand-alone Prescription Drug Plan

that the characteristics of hospitals with low service quality and high costs included those that were small and located in the southern regions compared with the hospitals with highquality services and low cost. ${ }^{48}$ Other factors contributing to the geographic variation in the HRM use included variations in physician-prescribing patterns, health plan formularies, and patient and prescriber preference. ${ }^{49}$ Future research is warranted for further investigation of the interaction between different Part D plan types, area characteristics, and patient health outcomes.

Identifying regions with higher prevalence of HRM use may better guide the current intervention programs such as pharmacist-provided MTM services to focus on these regions. MTM typically constitutes a comprehensive medication review (CMR) to identify medication-related problems, including HRM use among older adults. ${ }^{50}$ Several studies have demonstrated the value of MTM services in improving health outcomes in a variety of chronic conditions and settings. ${ }^{51-53}$ Although 1 study found that MA-PD providers with high CMR completion rates had lower HRM use among their beneficiaries, the association between CMR completion and HRM use was not observed among PDP beneficiaries. ${ }^{21}$ Leveraging community efforts to promote education related to the risk of HRM use in these high-risk regions may also reduce HRM use and associated consequences.

The strengths of this study included the following: (a) use of the PQA/CMS definition for HRM use that is currently employed to determine the Part D star ratings and evaluate plan performance in a large nationally representative data of Medicare Part D beneficiaries and (b) the inclusion of MA-PD and PDP populations to present the full spectrum of the Part D Medicare population, which had not been assessed in previous studies.

\section{Limitations}

Several limitations of this study are noteworthy to discuss. First, as with any study using claims data, we were not able to measure sociobehavioral information, the need or clinical rationale for HRM use for some beneficiaries, and physician and patient preferences in our study. Similarly, unmeasured confounders cannot be ruled out. Second, this study relied on the assumption that dispensed medications were consumed as prescribed. Third, regions with small sample sizes of Medicare beneficiaries may lead to unstable estimates of HRM use. Fourth, the clinical complexity may have been underestimated because the RxRisk score was calculated based on prescription claims data alone. For example, some patients with diabetes may only need lifestyle modifications instead of medication treatment. Finally, our study used data from 2011 to 2013 that we had access to. The study findings may not be generalizable to more recent years.

\section{Conclusions}

Substantial geographic variation in HRM use exists among older adults in Medicare, regardless of type of prescription 


\section{Geographic Variation in the Prevalence of High-Risk Medication Use Among Medicare Part D Beneficiaries by Hospital Referral Region}

drug plan from 2011 to 2013. Most areas with the highest prevalence of HRM use were located in the southern regions of the United States. Areas with high HRM prevalence may benefit from targeted interventions (e.g., MTM monitoring or alternative medication substitutions) to prevent potential adverse consequences.

\section{Authors}

CHANADDA CHINTHAMMIT, BSPharm, MS, PhD, Department of Pharmaceutical Sciences, College of Pharmacy, University of Arizona, Tucson, and Eli Lilly \& Company, Indianapolis, Indiana. SANDIPAN BHATTACHARJEE, BPharm, MS, PhD; DAVID R. AXON, PhD, MPharm, MS; MARION SLACK, PhD; and TERRI L. WARHOLAK, PhD, Department of Pharmacy Practice and Science, College of Pharmacy, University of Arizona, Tucson. JOHN P. BENTLEY, PhD, Department of Pharmacy Administration, School of Pharmacy, University of Mississippi, University, and DEBBIE L. WILSON, PhD, Department of Pharmaceutical Outcomes and Policy, College of Pharmacy, University of Florida, Gainesville. WEI-HSUAN LO-CIGANIC, PhD, MS, MSPharm, Department of Pharmaceutical Outcomes and Policy, and Center for Drug Evaluation and Safety, College of Pharmacy, University of Florida, Gainesville.

AUTHOR CORRESPONDENCE: Wei-Hsuan Lo-Ciganic, PhD, MS, MSPharm, Department of Pharmaceutical Outcomes E Policy, College of Pharmacy, University of Florida, PO Box 100496, 1225 Center Dr., HPNP Bldg., Rm. 3338, Gainesville, FL 32610-0496. Tel.: 352.273.6255; Email: wlociganic@cop.ufl.edu.

\section{DISCLOSURES}

No outside funding supported this study. The authors have nothing to disclose.

This study was presented as a poster at the International Society of Pharmacoeconomics and Outcomes Research (ISPOR) Asia Pacific Meeting; September 8-11, 2018; Tokyo, Japan.

\section{REFERENCE}

1. Bao Y, Shao H, Bishop TF, Schackman BR, Bruce ML. Inappropriate medication in a national sample of US elderly patients receiving home health care. J Gen Intern Med. 2012;27(3):304-10.

2. Centers for Medicare $\&$ Medicaid Services. Part $C \& D$ performance data. 2014 Part C \& D Medicare star ratings data. Available at: https://www.cms. gov/Medicare/Prescription-Drug-Coverage/PrescriptionDrugCovGenIn/ PerformanceData.html. Accessed August 11, 2020.

3. Davidoff AJ, Miller GE, Sarpong EM, Yang E, Brandt N, Fick DM. Prevalence of potentially inappropriate medication use in older adults using the 2012 Beers Criteria. J Am Geriatr Soc. 2015;63(3):486-500.

4. Egger SS, Bachmann A, Hubmann N, Schlienger RG, Krähenbühl S. Prevalence of potentially inappropriate medication use in elderly patients. Drugs Aging. 2006;23(10):823-37.

5. Fick DM, Mion LC, Beers MH, L Waller J. Health outcomes associated with potentially inappropriate medication use in older adults. Res Nurs Health. 2008;31(1):42-51
6. Gallagher PF, Barry PJ, Ryan C, Hartigan I, O'Mahony D. Inappropriate prescribing in an acutely ill population of elderly patients as determined by Beers' Criteria. Age Ageing. 2008;37(1):96-101.

7. Opondo D, Eslami S, Visscher S, et al. Inappropriateness of medication prescriptions to elderly patients in the primary care setting: a systematic review. PloS One. 2012;7(8):e43617.

8. Mangoni AA, Jackson SH. Age-related changes in pharmacokinetics and pharmacodynamics: basic principles and practical applications. Br J Clin Pharmacol. 2004;57(1):6-14.

9. Gurwitz JH, Field TS, Judge J, et al. The incidence of adverse drug events in two large academic long-term care facilities. Am J Med. 2005;118(3):251-58

10. Fu AZ, Jiang JZ, Reeves JH, Fincham JE, Liu GG, Perri III M. Potentially inappropriate medication use and healthcare expenditures in the U.S. community-dwelling elderly. Med Care. 2007;45(5):472-76.

11. Hyttinen V, Jyrkkä J, Valtonen H. A systematic review of the impact of potentially inappropriate medication on health care utilization and costs among older adults. Med Care. 2016;54(10):950-64

12. Beers MH, Ouslander JG, Rollingher I, Reuben DB, Brooks J, Beck JC. Explicit criteria for determining inappropriate medication use in nursing home residents. Arch Intern Med. 1991;151(9):1825-32.

13. American Geriatrics Society 2012 Beers Criteria Update Export Panel. American Geriatrics Society updated Beers Criteria for potentially inappropriate medication use in older adults. J Am Geriatr Soc. 2012;60(4):616-31.

14. Fick DM, Cooper JW, Wade WE, Waller JL, Maclean J, Beers MH. Updating the Beers Criteria for potentially inappropriate medication use in older adults: results of a U.S. consensus panel of experts. Arch Intern Med. 2003;163(22):2716-24.

15. Scarlatos MV. Toward a better understanding of high-risk medications in the elderly. Pharmacy Times. March 20, 2015. Available at: https://www pharmacytimes.com/publications/ajpb/2015/ajpb_marchapril2015/towarda-better-understanding-of--high-risk-medications-in-the-elderly. Accessed August 11, 2020.

16. Hung A, Perfetto EM. What are the incentives for Medicare prescription drug plans to consider long-term outcomes and cost? J Manag Care Spec Pharm. 2016;22(7):773-78. Available at: https://www.jmcp.org/doi/10.18553/ jmcp.2016.22.7.773

17. Pharmacy Quality Alliance. PQA medication safety measures. 2017. Available at: https://www.pqaalliance.org/medication-safety. Accessed August 25, 2020.

18. Erickson SC, Leslie RS, Patel BV. Is there an association between the high-risk medication star ratings and member experience CMS star ratings measures? J Manag Care Pharm. 2014;20(11):1129-36. Available at: https:// www.jmcp.org/doi/10.18553/jmcp.2014.20.11.1129.

19. Owen JA. Medicare star ratings: stakeholder proceedings on community pharmacy and managed care partnerships in quality: American Pharmacists Association and Academy of Managed Care Pharmacy. J Am Pharm Assoc. 2014;54(3):228-40.

20. Centers for Medicare $\&$ Medicaid Services. Medicare health $\&$ drug plan quality and performance ratings: 2013 Part C \& Part D technical notes. First plan preview. August 9, 2012. Available at: https://www.cms.gov/medicare/ prescription-drug-coverage/prescriptiondrugcovgenin/downloads/technicalnotes-2013-.pdf. Accessed August 11, 2020.

21. Almodovar AS, Axon DR, Coleman AM, Warholak T, Nahata MC. The effect of plan type and comprehensive medication reviews on high-risk medication use. J Manag Care Spec Pharm. 2018;24(5):416-22. Available at: https://www.jmcp.org/doi/10.18553/jmcp.2018.24.5.416.

22. Centers for Medicare $\&$ Medicaid Services. Updated prescriber-level Medicare data. August 18, 2016. Available at: https://www.cms.gov/ newsroom/fact-sheets/updated-prescriber-level-medicare-data. Accessed August 11, 2020. 


\section{Geographic Variation in the Prevalence of High-Risk Medication Use Among Medicare Part D Beneficiaries by Hospital Referral Region}

23. Dartmouth Institute for Health Policy and Clinical Practice. Dartmouth Atlas of Health Care. FAQ. 2020. Available at: https://www.dartmouthatlas. org/faq/. Accessed August 11, 2020.

24. Kilaru AS, Wiebe DJ, Karp DN, Love J, Kallan MJ, Carr BG. Do hospital service areas and hospital referral regions define discrete health care populations? Med Care. 2015;53(6):510-16.

25. Newhouse JP, Garber AM. Geographic variation in Medicare services. N Engl J Med. 2013;368(16):1465-68.

26. Zhang Y, Baicker K, Newhouse JP. Geographic variation in the quality of prescribing. N Engl J Med. 2010;363(21):1985-88.

27. Research Data Assistance Center (ResDAC). Master Beneficiary Summary File. 2017. Available at: https://www.resdac.org/cms-data/files/mbsf.

Accessed August 11, 2020.

28. Research Data Assistance Center (ResDAC). Part D Drug Event File. 2017. Available at: https://www.resdac.org/cms-data/files/pde. Accessed August 11, 2020.

29. National Committee for Quality Assurance. Medicare Special Needs Plans Performance Results: HEDIS 2015. 2015. Available at: https://www. cms.gov/Medicare/Health-Plans/SpecialNeedsPlans/Downloads/2015HEDIS-Report.pdf. Accessed August 11, 2020.

30. Centers for Medicare \& Medicaid Services. Part C and D performance data. 2015 star ratings and display measures. Available at: https://www.cms. gov/Medicare/Prescription-Drug-Coverage/PrescriptionDrugCovGenIn/ PerformanceData. Accessed August 11, 2020.

31. Academy of Managed Care Pharmacy, American Pharmacists Association. Medicare star ratings: stakeholder proceedings on community pharmacy and managed care partnerships in quality. J Am Pharm Assoc (2003). 2014;54(3):228-40

32. Xiao T, Thiele A. Analysis of Medicare prescription drug coverage enrollment. J Health Care Fin. 2016;42(3). Available at: https://www. healthfinancejournal.com/index.php/johcf/article/view/60. Accessed August 11, 2020

33. von Elm E, Altman DG, Egger M, Pocock SJ, Gotzsche PC, Vandenbroucke JP. The Strengthening the Reporting of Observational Studies in Epidemiology (STROBE) statement: guidelines for reporting observational studies. J Clin Epidemiol. 2008;61(4):344-49.

34. Pharmacy Quality Alliance. Use of high-risk medications in elderly (HRM). Available at: https://wwwll.anthem.com/provider/noapplication/fl/s0/ t0/pw_g261999.pdf?refer=culdesac\&name=ephc. Accessed August 11, 2020

35. Dartmouth Institute for Health Policy and Clinical Practice. The Dartmouth Atlas of Health Care. Research methods FAQ. 2017. Available at: https://www.dartmouthatlas.org/faq/\#research-methods-faq. Accessed August 11, 2020.

36. Wennberg JE, Fisher ES, Goodman DC, Skinner JS. Tracking the care of patients with severe chronic illness. The Dartmouth Atlas of Health Care 2008. Available at: https://www.dartmouth.edu/ jskinner/documents/2008_ Chronic_Care_Atlas.pdf. Accessed August 11, 2020.

37. Sloan KL, Sales AE, Liu C-F, et al. Construction and characteristics of the RxRisk-V: a VA-adapted pharmacy-based case-mix instrument. Med Care. 2003:41(6)761-74.

38. Farley JF, Harley CR, Devine JW. A comparison of comorbidity measurements to predict healthcare expenditures. Am J Manag Care. 2006;12(2):110-19.
39. Johnson ML, El-Serag HB, Tran TT, Hartman C, Richardson P, Abraham NS. Adapting the Rx-Risk-V for mortality prediction in outpatient populations. Med Care. 2006;44(8):793-97.

40. Fan VS, Maciejewski ML, Liu C-F, McDonell MB, Fihn SD. Comparison of risk adjustment measures based on self-report, administrative data, and pharmacy records to predict clinical outcomes. Health Serv Outcomes Res Method. 2006;6(1-2):21-36.

41. Vitry A, Wong SA, Roughead EE, Ramsay E, Barratt J. Validity of medication-based comorbidity indices in the Australian elderly population. Aust N Z J Public Health. 2009;33(2):126-30.

42. Fishman PA, Goodman MJ, Hornbrook MC, Meenan RT, Bachman DJ, Rosetti MCK. Risk adjustment using automated ambulatory pharmacy data: the RxRisk model. Med Care. 2003;41(1):84-99.

43. Donohue JM, Morden NE, Gellad WF, et al. Sources of regional variation in Medicare Part D drug spending. N Engl J Med. 2012;366(6):530-38.

44. Rothberg MB, Pekow PS, Liu F, et al. Potentially inappropriate medication use in hospitalized elders. J Hosp Med. 2008;3(2):91-102.

45. Lund BC, Charlton ME, Steinman MA, Kaboli PJ. Regional differences in prescribing quality among elder veterans and the impact of rural residence. J Rural Health. 2013;29(2):172-79.

46. Munson JC, Morden NE, Goodman DC, et al. The Dartmouth Atlas of Medicare Prescription Drug Use 2013. A Report of the Dartmouth Atlas Project. October 15, 2013. Available at: http://www.dartmouthatlas.org/ downloads/reports/Prescription_Drug_Atlas_101513.pdf. Accessed August 11, 2020.

47. Cubanski J, Neuman T, White C. The latest on geographic variation in Medicare spending: a demographic divide persists but variation has narrowed. The Kaiser Family Foundation. October 9, 2015. Available at: https://www.kff.org/medicare/report/the-latest-on-geographic-variationin-medicare-spending-a-demographic-divide-persists-but-variation-hasnarrowed/. Accessed August 11, 2020.

48. Jha AK, Orav EJ, Epstein AM. Low-quality, high-cost hospitals, mainly in South, care for sharply higher shares of elderly black, Hispanic, and Medicaid patients. Health Aff (Millwood). 2011;30(10):1904-11.

49. Lowes R. High-risk meds for elderly most prescribed in South, CMS says. Medscape. August 25, 2016. Available at: https://www.medscape.com/ viewarticle/867954?src=rss\#vp_1. Accessed August 11, 2020.

50. American Pharmacists Association. Medication therapy management services. 2019. Available at: https://www.pharmacist.com/medicationtherapy-management-services. Accessed August 11, 2020.

51. Johnson M, Jastrzab R, Tate J, et al. Evaluation of an academiccommunity partnership to implement MTM services in rural communities to improve pharmaceutical care for patients with diabetes and/or hypertension. J Manag Care Spec Pharm. 2018;24(2):132-41. Available at: https://www.jmcp. org/doi/10.18553/jmcp.2018.24.2.132.

52. Taylor AM, Bingham J, Schussel K, et al. Integrating innovative telehealth solutions into an interprofessional team-delivered chronic care management pilot program. J Manag Care Spec Pharm. 2018;24(8):81318. Available at: https://www.jmcp.org/doi/10.18553/jmcp.2018.24.8.813. Accessed August 11, 2020.

53. Axon DR, Taylor AM, Vo D, Bingham J. Initial assessment of an interprofessional team-delivered telehealth program for patients with epilepsy. Epilepsy Res. 2019;158:106235. 